\title{
Alternatif Kebijakan Pengendalian Pemotongan Sapi Bali Betina Produktif di Timor Barat
}

\author{
Maria Krova' ${ }^{1}$, J.G. Sogen ${ }^{1}$, Maria Y. Luruk ${ }^{1}$ \\ ${ }^{1}$ Fakultas Peternakan, Universitas Nusa Cendana \\ Jl. Adisucipto Penfui. Kotak Pos 104, Kupang 85001, NTT. Telp.(0380) 881084 \\ *Email korespondensi: mariakrova@staf.undana.ac.id
}

(Diterima: 23-8-2018; disetujui 20-9-2018)

\begin{abstract}
Abstrak
Salah satu persoalan yang terjadi di daerah sentra produksi adalah pemotongan betina produktif. Fenomena tersebut diduga terjadi pula di Timor Barat sebagai salah satu daerah kantong produksi sapi bali. Sapi bali adalah salah satu plasma nuftah yang memiliki persoalan sistemik karena melibatkan banyak pelaku. Penelitian ini bertujuan untuk mengetahui upaya pengendalian pemotongan betina produktif dalam manajemen dan kelembagaan aktual. Pendekatan pemahaman sistem agribisnis sapi bali di Timor Barat dilakukan dengan prespektif dinamika sistem. Informan kunci ditentukan melalui pemetaan pelaku dalam rantai pasok sapi bali. Penentuan informan kunci menggunakan metode snow ball sampling. Banyaknya informan kunci tergantung pada kejenuhan informasi yang diperoleh. Data, informasi, dan pengetahuan primer dikumpulkan berdasarkan observasi, focuss group diskusi (FGD), dan wawancara mendalam (indepth study) dengan informan kunci. Jenis data yang dikumpulkan terdiri atas: data numerik, data tertulis, dan model mental. Pemodelan dengan dinamika sistem akan menggunakan perangkat lunak Ventana Simulation (Vensim). Hasil analisis dan pembahasan menunjukkan manajemen dan kelembagaan aktual yang melibatkan berbagai pelaku dalam sistem ketersediaan daging sapi untuk pasar lokal belum memiliki peran untuk pengendalian pemotongan betina produktif. Kebijakan yang diperlukan untuk mengendalikan pemotongan sapi bali betina produktif, adalah meningkatkan calf crop dan menekan mortalitas.
\end{abstract}

Kata kunci: betina produktif, pemotongan, sapi bali, sistem, Timor Barat.

\begin{abstract}
One of the problems that occur in the center of production is slaughtering productive cows. This phenomenon is thought to occur in West Timor as one of the production center of bali cattle production. Bali cattle are one of the plasma nuftah which has systemic problems due to involve many actors. This study aims to determine the efforts to control the slaughtering of productive cows in actual management and institutions. An understanding approach to the bali cattle agribusiness system is carried out with a perspective dynamics system. Key informants were determined through mapping of actors in the supply chain of bali cattle. Determination of key informants is applying the snow ball sampling methods. Data are collected based on observation, FGD, and in-depth interviews. Data collected consists of: numeric and written data, and also mental models. Modeling with dynamics system will use Vensim software. The results show that actual management and institutions do not yet have a role to control the slaughtering of productive cows. The policy needed to control the slaughter of productive bali cows is to increase calf crop and reduce mortality.
\end{abstract}

Keywords: productive, slaughtering, bali cows, system, West Timor 


\section{PENDAHULUAN}

Salah satu persoalan yang cenderung meningkat di daerah sentra produksi adalah pemotongan betina produktif baik di Rumah Potong Hewan (RPH) maupun non RPH. Hasil penelitian Suardana, et al (2013) menunjukkan bahwa 99\% dari jumlah sapi betina yang dipotong di RPH Pesanggaran, dan $67,49 \%$ di RPH Mambal tergolong dalam kategori sapi betina produktif. Selanjutnya hasil penelitian Tawaf et al. (2013) di Pulau Jawa dan Nusa Tenggara, dalam periode studi (Juli sampai Agustus 2013) terjadi pemotongan sapi lokal betina umur produktif $31,04 \%$ dari jumlah sapi lokal yang dipotong. Fenomena yang sama diduga terjadi pula di daerah NTT sebagai salah satu wilayah kantong produksi sapi bali.

Sapi bali merupakan salah satu ternak plasma nuftah yang perlu dilestarikan hanya dengan pengembangbiakan. Pemotongan betina produktif secara berkelanjutan dapat menyebabkan musnahnya plasma nuftah ini. Sebagai suatu sistem, pengembangan sapi bali melibatkan banyak pihak dengan kepentingan berbeda menyebabkan pemotongan betina produktif di RPH maupun non RPH cenderung tinggi. Peternak di hulu berkepentingan untuk memenuhi kas rumahtangganya yang diandalkan dari ternak sapi. Sementara penjagal $\mathrm{RPH}$ dan non RPH di hilir berkepentingan untuk memenuhi kebutuhan pasar lokal dengan keuntungan yang besar. Pemerintah sendiri berkepentingan untuk mejaga kelestarian salah satu plasma nuftah ini. Pedagang perantara berkepentingan memenuhi permintaan pasar antar pulau yang cenderung meningkat sehingga mempertahankan rantai pasok sapi bali jantan yang sulit dipengaruhi oleh pelaku lainnya.
Penelitian ini dilakukan untuk mengetahui sejauhmana upaya pengendalian pemotongan betina produktif yang telah dilakukan oleh pihak yang terlibat dalam sistem ketersediaan daging sapi di pasar lokal, Timor Barat, serta kebijakan yang diperlukan untuk mengembangkan model manajemen dan kelembagaan dalam sistem agribisnis sapi bali yang mampu mengendalikan pemotongan betina produktif.

\section{METODE PENELITIAN}

Populasi dalam penelitian ini adalah semua pelaku utama dan pelaku pendukung dalam sistem agribisnis sapi bali yang terdapat di Timor Barat. Informan kunci ditentukan melalui pemetaannya dalam rantai pasok sapi bali baik pelaku maupun pendukung. Penentuan informan kunci pelaku menggunakan metode snow ball sampling dimulai dari hilir yaitu RPH dan pedagang antar pulau yang terdapat di setiap kabupaten dan kota. Banyaknya informan kunci tergantung pada kejenuhan informasi yang diperoleh serta hasil validasi informasi tentang perilaku dan struktur dunia nyata yang diperoleh dengan penstrukturan model dan pemahaman perilakunya.

Data, informasi, dan pengetahuan primer dikumpulkan berdasarkan observasi, focuss group diskusi (FGD), dan wawancara mendalam (indepth study) dengan informan kunci. Jenis data yang dikumpulkan terdiri atas: data numerik, data tertulis, dan model mental. Pemodelan dengan dinamika sistem akan menggunakan perangkat lunak Ventana Simulation (Vensim) PLE (Gambar 1). Hasil rancangan model selanjutnya divalidasi baik dimensi, struktur, perilaku maupun kebijakannya.

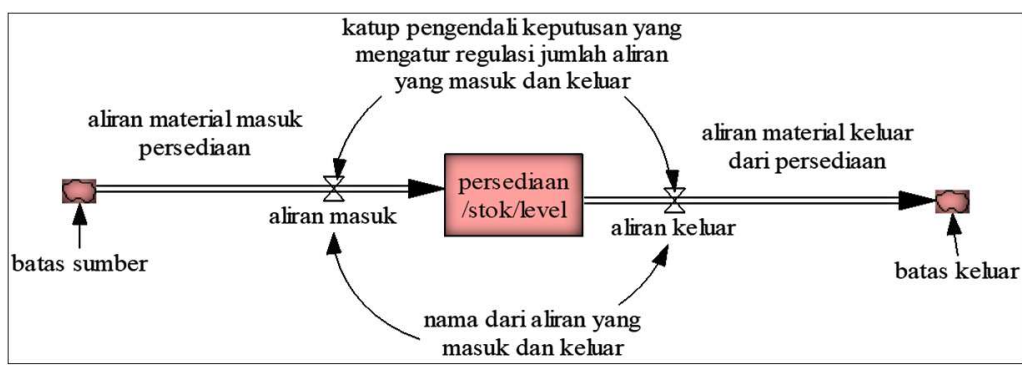

$\operatorname{Stock}(t)=\int_{t 0}^{t}[\operatorname{Inflow}(s)-\operatorname{Outflow}(s)] d s+\operatorname{Stock}(t 0)$

Gambar 1. Notasi pembuatan diagram persediaan dan aliran 


\section{HASIL DAN PEMBAHASAN}

\section{Pemahaman Sistem Rantai Pasok Sapi Bali Betina Produktif}

Hasil survei menunjukkan bahwa pelaku yang terlibat dalam produksi dan pemasaran sapi bali adalah peternak baik non kelompok maupun kelompok, pedagang pengumpul, koordinator pedagang pengumpul, penjagal Rumah Potong Hewan (RPH), penjagal non $\mathrm{RPH}$, pedagang pengecer daging sapi, dan pemerintah. Ternyata interaksi diantara semua pelaku tersebut hanya untuk memasarkan ternak sapi dan daging sapi. Tidak terdapat hubungan lainnya (kemitraan) yang terjalin antar peternak dengan pelaku pasar lainnya.

Pemahaman peran manajemen dan kelembagaan aktual dapat dijelaskan oleh Causal Loops Diagramm (Gambar 2). Diagram tersebut memperlihatkan bahwa sistem dalam rantai pasok sapi bali betina produktif meliputi 4 subsistem, yaitu: kas rumah tangga peternak, kebijakan pemerintah, ketersediaan ternak sapi untuk pasar lokal dan ternak sapi siap potong untuk pasar antar pulau. Ternyata pemotongan betina produktif hanya merupakan bagian dari sistem ketersediaan daging sapi untuk pasar lokal.

Pemotongan betina produktif ternyata merupakan akibat lanjut dari penawaran betina produktif oleh peternak produsen (Gambar 2). Artinya jika peternak tidak menawarkan betina produktifnya maka tidak akan pernah terjadi pembelian dan tersedia di RPH dan non RPH. Penawaran betina produktif oleh peternak disebabkan oleh desakan penawaran ternak sapi betina produktif. Desakan penawaran betina produktif merupakan akibat dari 2 hal, yaitu: pemanfaatan ternak sapi sebagai tabungan dan pemenuhan kebutuhan uang tunai rumahtangga. Jika motivasi pemeliharaan ternak masih sebagai tabungan dan bukan sebagai sumber pendapatan maka ternak sapi hanya akan dijual pada saat ada kebutuhan uang tunai. Ketika dijual pada saat tersebut maka kedudukan tawar menawar dari peternak akan lemah dan berdampak pada rendahnya harga ternak jenis apapun termasuk betina produktif. Salah satu subsistem yang memiliki pengaruh yang kuat terkait penjualan dan pemotongan betina produktif adalah kas rumahtangga peternak.
Gambar 2 memperlihatkan bahwa di antara semua variabel yang ada dalam diagram terdapat dua titik paling strategis atau pengungkit (leverages points) yaitu variabel kapasitas produksi sapi bali peternak di Timor Barat dan desakan penawaran ternak sapi. Terlihat bahwa masalah pada kedua titik tersebut telah menyebabkan 5 masalah lainnya dalam sistem. Kondisi ini mengindikasikan bahwa dengan melakukan intervensi kebijakan terhadap dua titik tersebut maka masalah pemotongan betina produktif dapat dikendalikan.

\section{Pemodelan Dinamis Sistem Ketersediaan Daging Sapi}

Mengetahui perilaku pemotongan sapi bali betina produktif dalam ketersediaan daging sapi di pasar lokal maka dikembangkan 2 model terkait yaitu persediaan dan kas pedagang RPH dan non RPH, serta permintaan pasar lokal. Sub model persediaan dan kas pedagang RPH dan non RPH ini menggambarkan persediaan sapi bali siap potong di pasar lokal, produksi daging, penjualannya, dan kas pedagang $\mathrm{RPH}$ berdasarkan permintaan pasar lokal (Gambar 3). Penambahan persediaan sapi siap potong di RPH berasal dari produksi sapi bali peternak untuk tujuan pasar lokal. Pilihan pedagang RPH membeli sapi bali yang bukan jantan hasil penggemukan tanpa cacat disebabkan harganya yang lebih murah dari $\mathrm{Rp} 500.000$,- hingga $\mathrm{Rp}$ $1.000 .000,-$. Pengurangan persediaan sapi bali siap potong di RPH disebabkan oleh pemotongan sapi dan penyusutan karena kematian yang diakomodir dalam fraksi penyusutan sapi di RPH yaitu sebesar 0,001 .

Penambahan persediaan daging sapi di RPH ini merupakan pemotongan sapi bali dari persediaan pedagang RPH. Untuk mendapat persediaan karkas di pedagang RPH ini telah dilakukan konversi karkas per ekor sapi bali atau diistilahkan fraksi daging per ekor sapi bali yaitu sebesar 41.25 persen. Menurut Harmini, et al, (2011) angka tersebut diperoleh dari, karkas per ekor sapi rata-rata sebesar 55 persen dengan kandungan daging sebesar 75 persen dari karkas. Tidak semua daging yang diproduksi oleh RPH terjual oleh karena itu diakomodir fraksi penyusutan daging di RPH yaitu sebesar 0,0595 . 


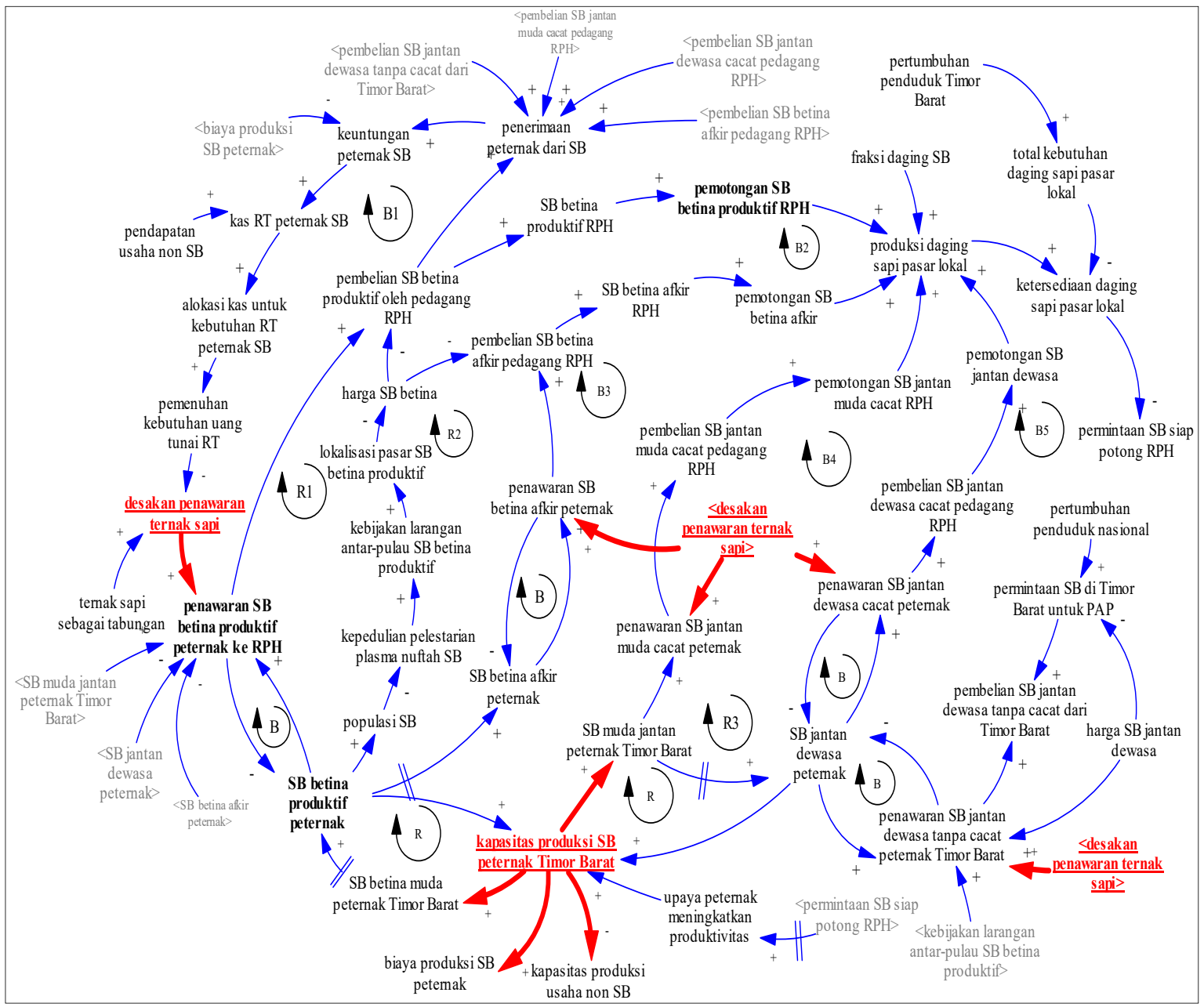

Gambar 2. Causal loops diagramm rantai pasok sapi bali betina produktif

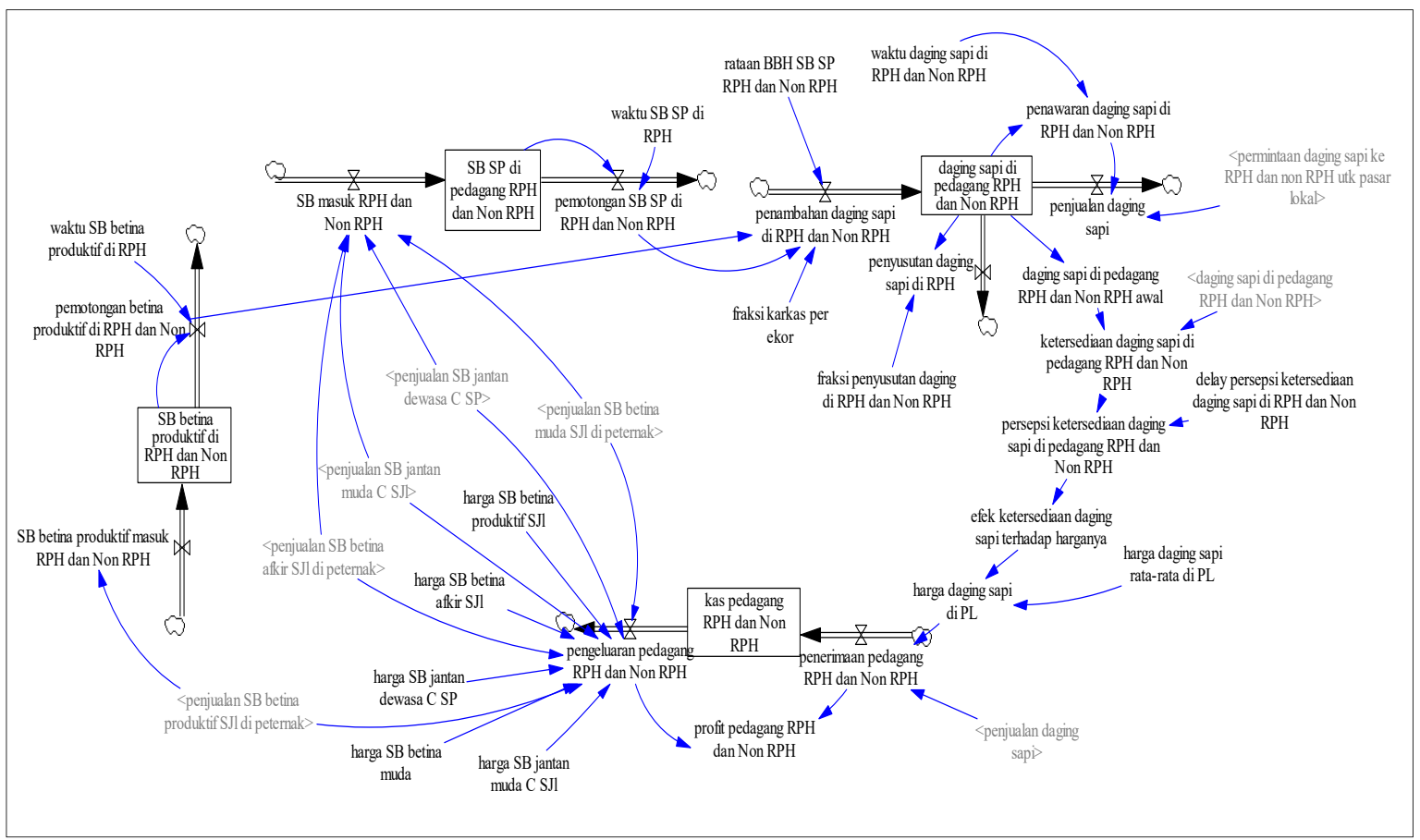

Gambar 3. Sub model persediaan dan kas pedagang RPH dan non RPH 
Persediaan daging di RPH ini menjadi dasar penurunan harga daging sapi di pasar lokal karena disitu terjadi interaksi penawaran dan permintaan sehingga terjadi penjualan daging sapi. Penurunan harga daging ini melalui tahapan analisis ketersediaan, persepsi ketersediaan, dan efek dari persepsi terhadap harga. Harga yang terjadi dan penjualan daging sapi ini menjadi dasar peroleh penerimaan bagi kas pedagang RPH. Harga daging sapi lokal diperoleh dari perkalian antara harga daging sapi rata-rata di pasar lokal (Rp 90.000,- per kg) dengan efek ketersediaan daging sapi terhadap harga daging sapi. Nilai hasil penjualan daging dengan harga tersebut merupakan penerimaan bagi kas pedagang RPH. Kas pedagang RPH ini digunakan kembali untuk membelanjakan sapi yang ditawarkan oleh peternak. Untuk itu kas pedagang RPH ini akan menjadi dasar bagi pedagang RPH dalam mengajukan permintaan sapi. Semakin likuid kas yang dimiliki pedagang RPH maka permintaannya akan semakin mendekati kebutuhannya. Sub model ini terkait dengan sub model persediaan dan kas peternak dan pasar lokal.

Pedagang daging sapi RPH mendapatkan sapi bali dari peternak, sedangkan karkas yang diproduksi dijual untuk pasar lokal. Sub model pasar lokal meng-gambarkan pertumbuhan pasar lokal di Timor Barat yang diakibatkan oleh jumlah penduduk dan laju pertumbuhan penduduk yang saat ini. Pada tahun 2014 titik awal simulasi model jumlah penduduk Timor Barat sebesar 1.797.415 orang dan laju pertumbuhan penduduk mencapai 0,0093 persen per tahun atau 0,000775 per bulan (Gambar 4). Tingkat konsumsi daging sapi per kapita penduduk Timor Barat adalah $0,3749 \mathrm{~kg} /$ orang/bulan (dihitung berdasarkan data BPS NTT, 2017). Selanjutnya dapat diperhitungkan total kebutuhan daging sapi yang dibutuhkan penduduk. Kebutuhan daging tersebut ditawarkan baik dari Rumah Potong Hewan (RPH) maupun dari Non RPH. Sub model pasar lokal terkait dengan sub model persediaan daging di RPH dan persediaan dan kas peternak.

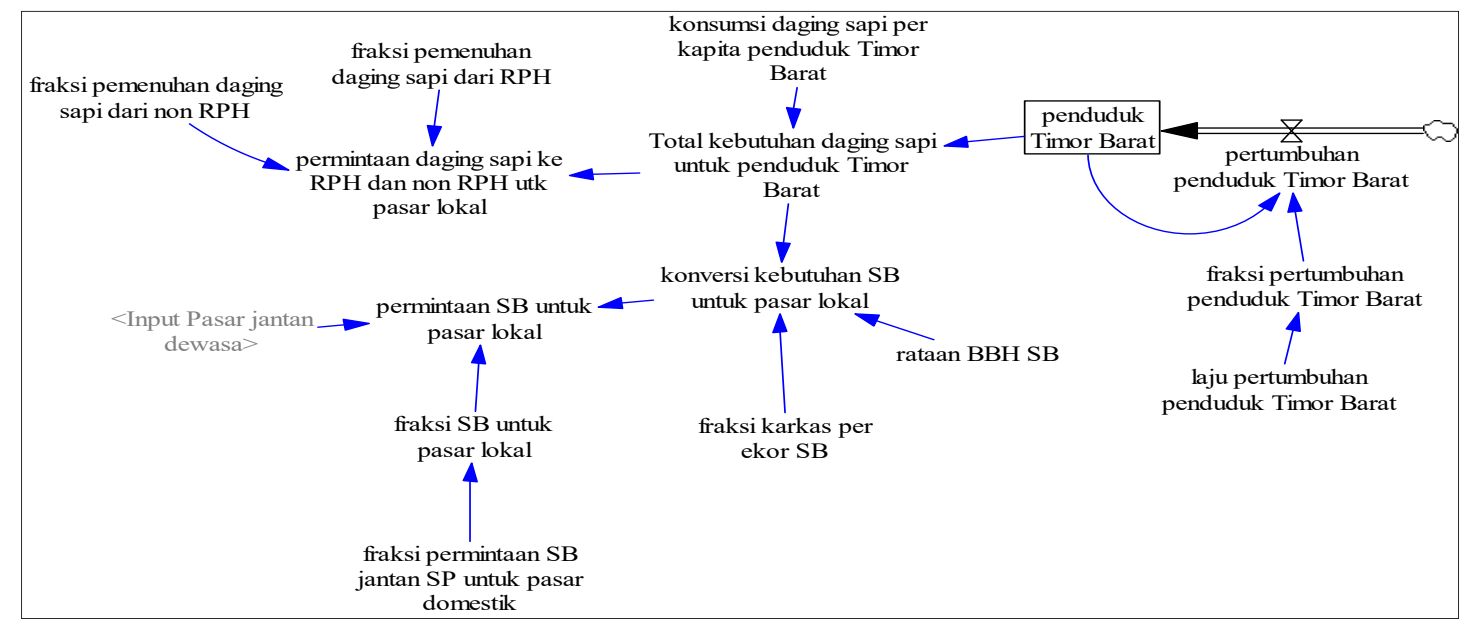

Gambar 4. Sub model pasar lokal

\section{Validasi Model}

Agar dapat membangun kepercayaan terhadap model tersebut maka telah dilakukan berbagai pengujian validasi. Sterman (2000) membahas uji yang dapat digunakan untuk menilai model yang dinamis yang diadaptasi dan dikembangkan dari Forrester dan Senge (1980). Pengujian model dapat dikelompokan dalam 3 uji, yaitu: uji struktur model, uji perilaku model, dan uji implikasi kebijakan dari model.

Sub model pasar lokal menggambarkan pertumbuhan pasar lokal di Timor Barat yang diakibatkan oleh jumlah penduduk dan laju pertumbuhan penduduk yang saat ini. Pada tahun 2014 titik awal simulasi model jumlah penduduk Timor Barat sebesar 1.797.415 orang dan laju pertumbuhan penduduk mencapai 0,0093 persen per tahun atau 0,000775 per bulan (Gambar 4). Tingkat konsumsi daging sapi per kapita penduduk Timor Barat adalah 0,3749 kg/orang/bulan (dihitung berdasarkan data BPS NTT, 2017). Selanjutnya dapat diperhitungkan total kebutuhan daging sapi yang dibutuhkan penduduk. Kebutuhan daging tersebut ditawarkan baik dari Rumah Potong 
Hewan (RPH) maupun dari non RPH. Sub model pasar lokal terkait dengan sub model persediaan daging di RPH dan persediaan dan kas peternak.

Pengujian terhadap kemampuan model yang dibangun menimbulkan reproduksi perilaku yang sesuai dengan sistem dalam dunia nyata, telah dilakukan beberapa pengujian statistik, seperti: r, RMSPE, dan uji Theil ( $\mathrm{U}^{\mathrm{M}}$, $\mathrm{U}^{\mathrm{S}}$, dan $\mathrm{U}^{\mathrm{C}}$ ). Hasil pengujian tersebut menunjukkan bahwa data historis (tahun 20142017) dua variabel (populasi ternak sapi dan penduduk Timor Barat) dan data hasil simulasi memiliki korelasi yang tinggi maka model yang ada mampu menggambarkan sistem rantai pasok sapi bali betina produktif sesuai dengan dunia nyata. Jika Root Mean Square Percent Error (RMSPE) hasil pengujian statistik menunjukkan nilai yang relatif dibawah 0,2 menunjukkan bahwa koefisien Theil (Theil's Inequality Coeficient atau U) yang bermanfaat untuk mengetahui kemampuan model valid untuk melakukan peramalan. Demikian pula halnya jika nilai proporsi bias $\left(\mathrm{U}^{\mathrm{M}}\right)$ dan nilai proporsi varians $\left(\mathrm{U}^{\mathrm{S}}\right)$ dari model sangat kecil mendekati nol, dimana berturut-turut berkisar dari 0,$24 ; 0,086$ dan 0,43 . Sedangkan nilai proporsi covarians $\left(\mathrm{U}^{\mathrm{C}}\right)$ relatif besar berkisar dari $(0,679-0,919)$ (Tabel 1).

Tabel 1. Rekapitulasi pengujian statistik data historis dan hasil simulasi

\begin{tabular}{ccc}
\hline & Populasi Sapi & $\begin{array}{c}\text { Populasi Penduduk } \\
\text { Timor Barat }\end{array}$ \\
\hline $\mathrm{r}$ & 0,999 & 0,999 \\
$\mathrm{RMSPE}$ & 0,021 & 0,002 \\
$\mathrm{U}^{\mathrm{M}}$ & 0,169 & 0,085 \\
$\mathrm{U}^{\mathrm{S}}$ & 0,243 & 0,086 \\
$\mathrm{U}^{\mathrm{C}}$ & 0,679 & 0,774 \\
\hline
\end{tabular}

\section{Perilaku Pemotongan Betina Produktif}

Setelah model yang dibangun telah valid selanjutnya dilakukan simulasi untuk mengetahui perilaku dari variabel yang diamati. Hasil simulasi pada Gambar 5 a, memperlihatkan bahwa permintaan daging sapi jauh lebih tinggi dibandingkan penawarannya. Penawaran dan permintaan daging sapi saat ini hingga 5 tahun ke depan masih memiliki kesenjangan yang cukup lebar. Artinya peternak Timor Barat masih memiliki peluang produksi untuk memenuhi kebutuhan pasar lokal dan antar pulau. Peluang tersebut harus dipenuhi dengan memproduksi sapi siap potong yang non produktif. Produksi sapi siap potong non produktif harus didukung oleh kebijakan mengendalikan pemotongan betina produktif.

Simulasi yang ditunjukkan pada Gambar 5 memperlihatkan perilaku pemotongan sapi bali betina produktif di RPH dan non RPH yang cenderung meningkat. Peningkatan jumlah ini sejalan dengan meningkatnya populasi sapi bali termasuk betina produktif. Kondisi ini menunjukkan bahwa manajemen dan kelembagaan baik yang melibatkan berbagai pihak di atas belum berperan maksimal dalam pengendalian pemotongan betina produktif. Sejauh ini telah dilakukan sosialisasi larangan pemotongan betina produktif di tingkat pedagang $\mathrm{RPH}$ namun penawaran betina produktif dari peternak tetap terjadi menyebabkan pembelian dan ketersediaannya di tingkat pedagang tetap berlangsung.

\section{Upaya Pengendalian Pemotongan Betina Produktif}

Upaya pengendalian pemotongan sapi Bali betina produktif membutuhkan kebijakan mikro di tingkat peternak. Satu diantaranya adalah meningkatkan kapasitas produksi. Upaya meningkatkan kapasitas produksi dapat didorong melalui skenario peningkatan paramater produksi yang masih lemah, antara lain: calf crop dan mortalitas.

Skenario I merupakan representasi dari peningkatan calf crop yang akan mempengaruhi peningkatan panen pedet dalam budidaya pengembangbiakan. Ketika panen pedet dapat ditingkatkan maka populasi sapi bali akan meningkat (Gambar 6). Hasil simulasi ini menunjukkan bahwa dengan meningkatkan calf crop sebesar 18,37 persen (skenario I A) dan 32,65 persen (skenario I B) dari calf crop aktual sebesar 49 persen sehingga menjadi 55 persen dan 65 persen maka populasi sapi bali anak jantan dan betina meningkat. Dinamika populasi ini akan terus meningkat sejalan dengan perubahan waktu. 


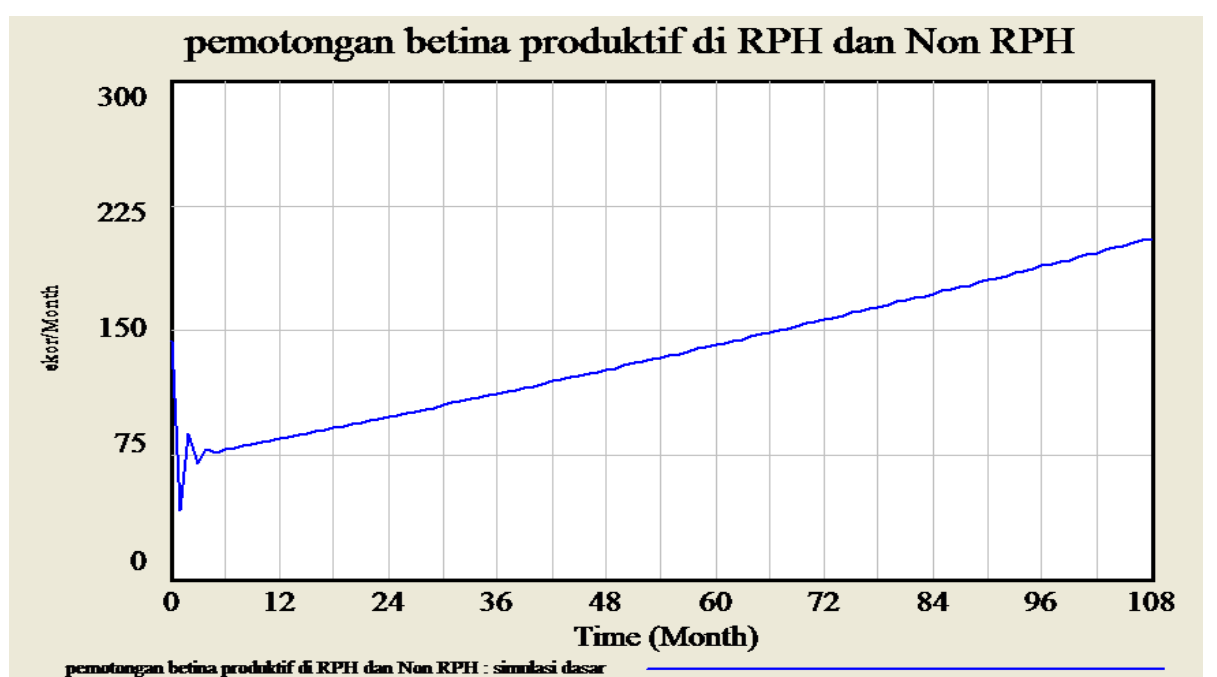

Gambar 5. Pemotongan sapi bali di RPH dan non RPH di Timor Barat

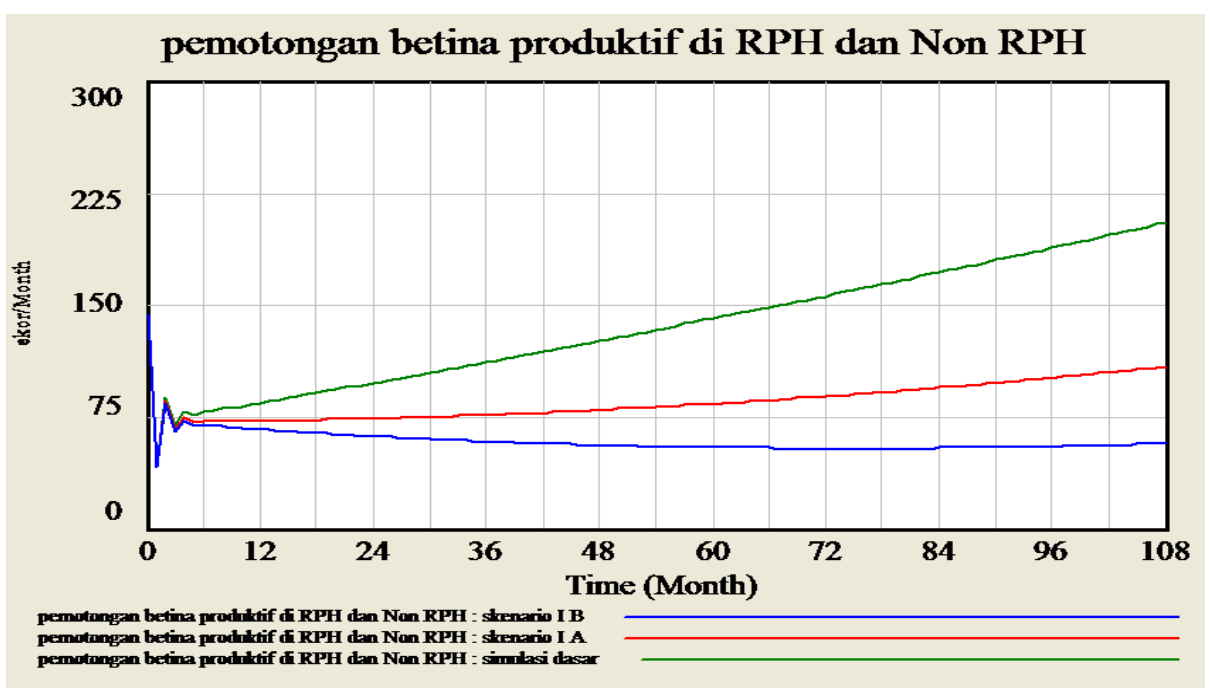

Gambar 6. Hasil simulasi skenario I terhadap pemotongan sapi bali betina produktif

Hasil simulasi menerapkan skenario I menunjukkan pengurangan pemotongan sapi bali betina produktif (Gambar 6). Pengurangan ini disebabkan jumlah sapi siap jual non betina produktif di tingkat peternak meningkat sehingga mengurangi desakan penawaran betina produktif untuk pemenuhan kebutuhan rumahtangga. Artinya skenario I ini dapat digunakan sebagai salah satu kebijakan untuk pengendalian pemotongan sapi bali betina produktif.

Penerapan skenario peningkatan calf crop di atas hanya dapat dijalankan jika peternak mau menerapkan berbagai teknologi terkait. Salah satu teknologi yang sudah dikenal adalah inseminasi buatan. Walaupun teknologi ini baik untuk tujuan di atas namun dalam pelaksanaannya banyak mengalami kendala baik dari inseminatornya, peternaknya, maupun sapi akseptornya. Oleh karena itu, walaupun kebijakan ini bukan merupakan suatu hal yang baru namun pemerintah perlu kembali mengevaluasi dan memperbaiki aspek terkait penerapan teknologi ini di tingkat peternak. Keberhasilan pemanfaatan teknologi inseminasi buatan dalam kelompok pilot project dapat menjadi indikator bagi peternak untuk menerapkan teknologi inseminasi buatan.

Pemanfaatan teknologi inseminasi Buatan ini dianggap penting mengingat sapi 
bali jantan yang dimiliki peternak semakin langka baik dalam kuantitas maupun kualitas. Kelangkaan ini disebabkan karena sapi bali jantan memiliki nilai jual yang relatif tinggi sehingga peternak lebih banyak memilih untuk menjualnya. Semakin sulitnya sapi pejantan yang dimiliki atau yang dapat diperoleh tersebut menyebabkan sistem kawin alami dalam jangka panjang tidak dapat diandalkan lagi oleh peternak. Untuk itu perlu adanya upaya untuk meningkatkan produktivitas sapi bali dengan memanfaatkan teknologi inseminasi buatan yang sudah tersedia.

Peternak Timor Barat pernah menerapkan teknologi inseminasi buatan dalam upaya meningkatkan produktivitasnya. Namun karena tingkat keberhasilannya rendah serta risiko kematian anak dan induknya relatif tinggi menyebabkan petani enggan untuk menerapkannya kembali. Hal yang sama ditemukan di Kabupaten Pringsewu oleh Febrianthoro et al. (2015), bahwa conception rate (CR) pada sapi bali setelah dilakukan inseminasi Buatan adalah 50,38\%. Indikator ini menunjukkan kurang berhasilnya Inseminasi Buatan. Di Timor Barat, penyebab rendahnya CR adalah: (1) peternak terlambat melaporkan berahi sapi kepada petugas inseminator, (2) adanya kelainan pada alat reproduksi induk sapi, (3) inseminator kurang terampil, (4) fasilitas pelayanan inseminasi terbatas, dan (5) kurang lancarnya transportasi.

Diharapkan dengan memperbaiki kembali faktor-faktor yang menyebabkan ketidakberhasilan inseminasi buatan di atas upaya peningkatan kapasitas produksi tercapai. Hal-hal tersebut, antara lain sosialisasi yang intensif maka pengetahuan peternak akan pentingnya inseminasi buatan dan meningkatkan kompetensi inseminator. Dengan demikian peternak akan semakin banyak yang memanfaatkan teknologi tersebut.

Skenario II dilakukan dalam upaya menekan mortalitas sapi bali. Dalam kondisi aktual tingkat kematian sapi bali anak 26,7 persen, muda 2 persen, betina produktif 15 persen, dan jantan dewasa 1 persen. Terlihat bahwa tingkat kematian terbesar adalah pada tahap pertumbuhan pedet karena tidak didukung oleh pemberian pakan dengan kuantitas dan kualitas yang memadai. Oleh karena itu, dalam manajemen usaha ternak sapi yang menerapkan skenario perlu ditingkatkan kualitas dan kuantitas pakannya. Peningkatan kualitas pakan dapat dilakukan dengan pemberian suplemen. Penambahan suplemen hanya dilakukan pada anak karena pada umur tersebut masih sangat rawan risiko kematian.

Skenario di atas sesuai dengan hasil penelitian Jelantik et al. (2008) dan Mullik et al. (2008), menggunakan suplemen yang terdiri dari pakan lokal berikut ini: jerami rumput alam (10\%), dedak padi (26\%), tepung jagung (35 $\%)$, tepung daun lamtoro (15\%), dan tepung ikan (14\%). Semua jenis pakan lokal, kecuali tepung ikan cukup banyak tersedia di tingkat peternak dengan harga yang relatif murah sehingga dengan mudah peternak dapat mengadopsi teknologi pakan tersebut. Tepung ikan dapat diperoleh dari beberapa pasar lokal. Skenario ini diterapkan dengan mengurangi angka mortalitas yaitu dari 26,7 persen menjadi 15 persen (skenario II A) dan 5 persen (skenario II B). Mullik et al. (2008), melaporkan bahwa suplementasi pakan pada level satu persen ideal meningkatkan BBH anak sapi, namun direkomendasikan untuk menggunakan level dua persen untuk menekan tingkat kematian anak sapi. Hasil simulasi menerapkan skenario II menunjukkan bahwa dengan menekan angka mortalitas di atas terjadi pertambahan populasi baik dengan skenario IIA maupun II B. Jika populasi sapi bali meningkat maka ketersediaan sapi bali siap jual non betina produktif yang ditawarkan meningkat. Hasil simulasi skenario II menunjukkan bahwa semua kebijakan yang dilakukan untuk menekan mortalitas mampu untuk mengendalikan pemotongan betina produktif (Gambar 7). Dapat dijelaskan bahwa dengan adanya upaya menekan mortalitas menyebabkan ketersediaan sapi bali selain betina produktif meningkat sehingga ketika peternak terdesak oleh kebutuhan uang tunai maka yang ditawarkan adalah sapi bali non betina produktif. Dengan demikian dapat dikatakan bahwa kebijakan menekan mortalitas dalam sistem dapat mengendalikan pemotongan betina produktif di tingkat RPH dan non RPH. 


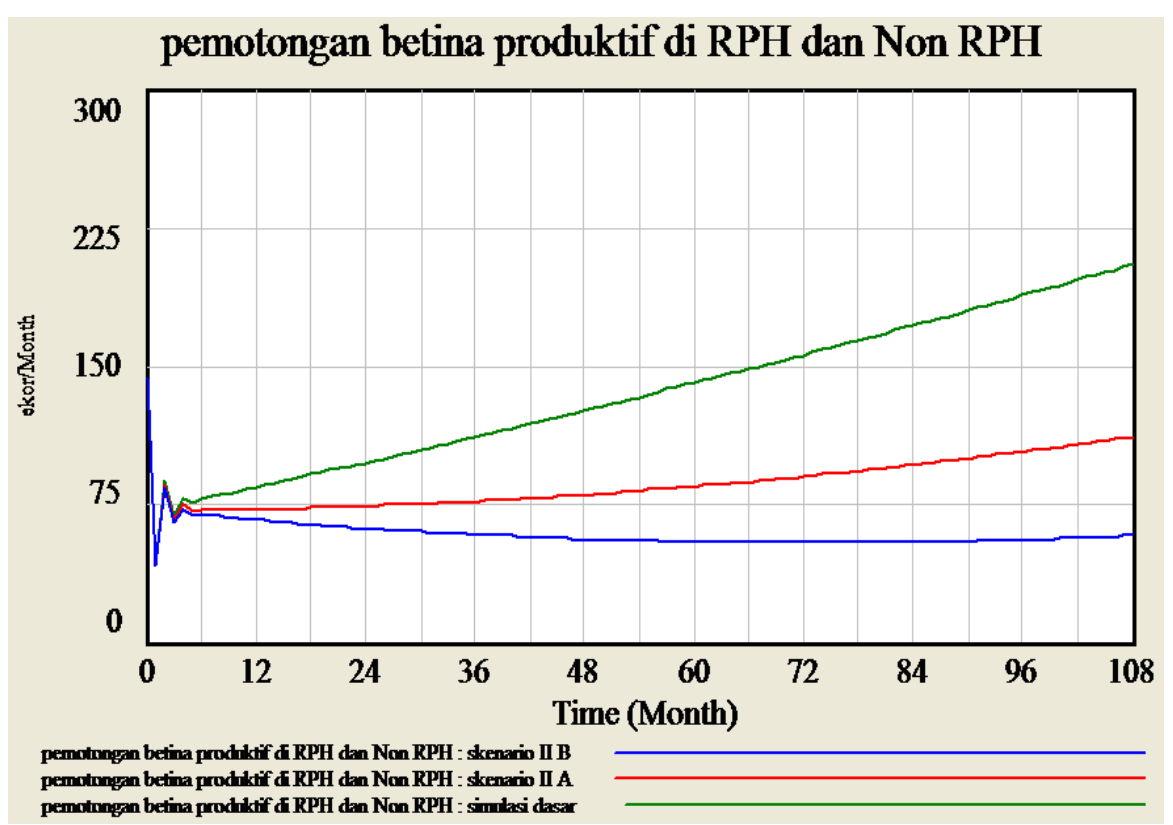

Gambar 7. Hasil simulasi skenario II terhadap pemotongan SB betina produktif

\section{KESIMPULAN}

Berdasarkan hasil dan pembahasan disimpulan bahwa manajemen dan kelembagaan aktual yang melibatkan banyak pihak dalam sistem ketersediaan daging sapi lokal belum memiliki peran untuk pengendalian penjualan dan pemotongan betina produktif. Alternatif kebijakan yang diperlukan untuk mengendalikan pemotongan sapi bali betina produktif adalah dengan meningkatkan calf crop dan menekan mortalitas.

Disarankan peningkatkan pemahaman dan kesadaran peternak tentang ternak sebagai sumber pendapatan dan bukan tabungan serta literasi perbankan dan perkoperasian. Perlu mengembangkan inovasi teknologi, antara lain: inseminasi buatan dengan membenahi segala kelemahan-kelemahannya dan pemanfaatan suplemen di tingkat peternak untuk meningkatkan kapasitas produksi.

\section{DAFTAR PUSTAKA}

BPS NTT, 2017. Provinsi Nusa Tenggara Timur Dalam Angka. Biro Pusat Statistik Provinsi NTT, Kupang.

Febrianthoro, F., M. Hartono, dan S. Suharyati. 2015. Faktor-faktor yang mempengaruhi conception rate pada sapi bali di Kabupaten Pringsewu.
Jurnal Ilmiah Peternakan Terpadu 3 (4):239-244.

Forester, J.W. \& P.M. Senge. 1980. Test for Building Confidence in System Dynamics Models. TIMS studies in Management Science 14:209-228. North-Holland Pub. Company.

Harmini, R. W. Asmarantaka, dan J. Atmakusuma, 2010. Model dinamis ketersediaan daging sapi nasional. Jurnal Ekonomi Pembangunan 12(1): 128-146.

Jelantik, I.G.N., M.L. Mullik, C.L. Penu, J. Jeremias, \& R. Copland. 2008. Improving calf survival and performance by supplementation in bali cattle. Australian Journal of Experimental Agriculture 48:954-956.

Madarisa, F., Edwardi, \& A. Arman, 2013. Kegiatan insentif dan penyelamatan sapi dan kerbau betina produktif di Sumatera Barat 2011-2012. Jurnal Peternakan Indonesia 15(1):26-34.

Mullik, M.L., A.I.G.N. Jelantik, \& R.S. Copland. 2008. Post weaning effects of supplementing bali cattle (Bos sondaicus) calves prior to weaning in villages of West Timor, Indonesia. 
Proc. Aust. Soc. Anim. Prod. 2010.

Vol. 28.

Sterman, J.D. 2000. Business Dynamics: System Thinking And Modelling For Complex World. Irwin McGraw Hill. Boston.

Suardana, I. W., I M. Sukada, I K. Suada1, \& D.A. Widiasih, 2013. Analisis jumlah dan umur sapi bali betina produktif yang dipotong di Rumah Pemotongan Hewan Pesanggaran dan Mambal Provinsi Bali. Jurnal Sains Veteriner 31(1):43-48

Tasrif, M. 2012. Analisis Kebijakan Menggunakan Model System Dynamycs. Development Studies Foundation, ITB. Bandung.

Tawaf, R., O. Rachmawan, C. Firmansyah. 2013. Pemotongan Sapi Betina Umur Produktif dan Kondisi RPH di Pulau Jawa dan Nusa Tenggara. Workshop Nasional: Konservasi dan Pengembangan Sapi Lokal. Fakutas Peternakan Unpad, 13 November 2013. 